\title{
Shared Agency: A Planning Theory of Acting Together
}

\author{
Michael E. Bratman \\ Oxford: Oxford University Press, 2014, 219 or.
}

DOI: $10.1387 /$ gogoa.17256

Shared agency eskala txikiko ekintza kolektiboari buruzko lana da, jarduera sozialak ekite indibidualarekin daukan harremanaren ingurukoa. Ekintza kolektiboen gertaerarako baldintza nahikoak bilduko lituzketen baliabide kontzeptual, metafisiko eta normatiboen ingurukoa ere bada. Liburua osatzen duten zortzi ataletan ${ }^{1}$ zehar, autorearen «asmoen plangintza teoria» ekintza sozialaren esparrura eramana izaten ikusiko dugu, plano indibidualaren eta sozialaren arteko jarraikortasuna nabarmentzen duen estrategia baten barruan (1. kapitulua). Ondoren, bai helburu horretarako beharrezkoak diren «eraikitze-bloke» ezberdinak («kateatze», «saretze», «uste», «laguntzarako disposizio» edota «publikotasuna») (2. eta 3. kap.), bai eskala txikiko sozializazioak eusten eta agerrarazten duen oinarrizko tesia aurkezten dira (4. kap.). Bestalde, lanak proposatutako ereduak elkarrenganako obligazioekiko izan dezakeen lotura (5. kap.), jarduera kolektiboak subjektu kolektiboen existentziarekin eduki dezakeena (6. kap.) zein, azkenik, deliberazio eta ekiteko politika partekatuen inguruko atala (7. kapitulua) ere eskaintzen ditu. Finean, liburua autorearen ekintzaren filosofiarako ekarpenen jarraipena da, betiere, noski, plano kolektibo (murriztu) batean zentraturik.

Michael Bratmanen «asmoen plangintza teoriak» ekintzaren inguruko hausnarketa filosofikoa elikatzeko gai dela erakutsi du proposatu zen ga-

\footnotetext{
1 Atalen izenburuak honako hauek dira: 1. Jendetasun eta Jarduera Planifikazioa; 2. Eraikitze Blokeak, lehenengo partea; 3. Eraikitze Blokeak, bigarren partea; 4. Jendetasun Modestuaren Eraikuntza; 5. Jendetasun Modestua eta Elkarrenganako Obligazioa; 6. Talde Agenteak Talde Subjekturik gabe; 7. Deliberazio Partekatua, Alor Komuna; Konklusioa: Agente Planifikatzaile Interkonektatuak.
} 
raitik $^{2}$. Hautaketa Arrazionalaren teoria tradizionalak eskainitako agentearen ereduaren gabeziak nabarmendu zituzten bat eginez (nabarmenki, Herbert Simonen arrazionaltasun mugatuaren teoria), baina independienteki, Bratmanen asmoaren teoria, agente arrazionalen mugak (kognitiboak adib.) kontuan hartuz, agente horien helburuei begirako ekintzak gauzatu ahal izateko beharrezkoak zaizkien mekanismo psikologikoetan, bereziki asmoetan, zentratzen da. Asmoek (etorkizunari bideratuak, plangintza-estrukturak) paper egonkortzailea beteko lukete, birtualki etengabekoak izan litezkeen deliberazio eta birpentsatze-egoerak (eta horiek dakarten baliabide-xahuketa) bideratzeko kapazak. Beste era batean esanda, asmoek (plan-egoerek) ekintzaren antolakuntzarako rol jakin eta zentralak betetzen dituzte agenteen psikologian. Rol hauek, funtsean, asmo-arrazionaltasunaren arauak lirateke (trinkotasun edota bitarteko eta helburuaren arteko koherentzia, besteak beste). Ekintzaren azalpenerako paper garrantzitsuaz gain, arau hauen jarraipenean norberaren (denboran zeharkako) planifikatze-estrukturaren zein pertsonen arteko ekite sozialaren erdigunea ikusten du Bratmanek.

Asmoan zentratutako teoria hau, bestalde, ekintza azaltzeko uste eta desiretan zentratutako eskemetatik (Davidsonena, esaterako) harago joaten saiatzen da, ez baititu horiek agentearen psikologia eta ekintza arrazionalaren (uste baino konplexuagoak diren fenomenoak) azalpenerako nahikotzat jotzen, ezta asmoak usteen multzoekin identifikatzen ere. Horrek ez du islatzen, inolaz ere, Bratmanek elementu teoriko berriak sartzeko joera sistematikorik duenik. Izan ere, segituan ikusiko dugun moduan, Bratmanen ekintza partekaturako hurbiltze teorikoaren kasuan, autoreak azalpenerako ezinbestekoak ez diren elementuen sartzea baztertuko du, jatorriz banakoen kasuei aplikatutako ekintzaren teoriarekiko jarraikortasuna bultzatuz.

Esan bezala, Shared Agency eskala txikiko nahitako ekintza kooperatibo, partekatuen kasuetara mugatuta dago: bi pertsonak elkarrekin kantatzea, hiri jakin batera elkarrekin joatea edo etxe bat elkarrekin margotzea dira eskainitako adibide sarrienak. Kasu mota horien azalpena ekintza indibiduala azaltzeari begira garatutako teoriaren esku gera daitekeela, funtsean ezer berririk erabili gabe, uste du Bratmanek: hona hemen teoriaren izaera emankorra eta alde kontserbadorea. Horrela, beste teoriko batzuek, beharrik gabe Bratmanen juzguan, sartutako elementu kolektibo primitiboak («Gu-asmoak», «Baterako konpromiso», etab.) soberan egongo lirateke.

Helburua, finean, ekintza (planifikatu ${ }^{3}$ ) konpartituaren oinarrizko elementu (nahikoak) eskaintzea da, ekintza (planifikatu) indibidualaren eta

\footnotetext{
2 Bratmanen ekintzaren filosofiarako ekarpenen eta bere testuinguruaren berri izateko, ikus Yaffe eta Vargas (2014). Hemen eskainitako sarreratxoa horretan oinarritzen da.

3 Autoreak (24. or.) pertsonen ekonomia psikikoak bestelako abileziak eta gaitasunak («norberaren planak modu eskematiko eta kontzeptualki irekian ezaugarritzeko, eta denbora pasa
} 
sozialaren arteko jarraikortasun «sakona» serio hartuz (jarraikortasun tesia deritzona). Joko-teoriaren oreka estrategikoan zein pertsonen arteko obligazioetan oinarritutako ereduetatik ihes, desio-uste eredu filosofikotik harago doan «indibidualismo handitu» bat bilatzen du egileak. Bere proiektuan ekintza konpartituetan inplikatutako banakoen asmoak (plan egoerak) zentralak izango direla esan beharrik ere ez dago, beraz.

Baina, zer dira orduan, bere estrategiaren barruan, asmo partekatuak? Finean, partaide bakoitzaren asmoei itsatsitako plan-egoerak, testuinguru egoki batean eta modu egokian elkar konektaturik. Beste era batean esanda, asmo konpartituen «izaera konpartitua» bakoitzaren planen edukietan datza, bakoitzaren «psikologia planifikatzaile»aren arteko elkar loturak eta elkarrekiko mendekotasunarekin batera. Plan-egoerak bakoitzaren (denboran zeharkako) ekitearen antolamenduan jokatutako, paper «interpertsonal» garrantzitsua (antolaketa sozialean alegia) ere bete dezakeela ikusten du Bratmanek. Asmo konpartituak gizabanakoen asmoak dira beraz, ekite konpartituei (gure ekiteei alegia) apelatzen dieten edukia duten asmo indibidualak. Nik guk elkarrekin dantzatzeko asmoa daukat, Zuk guk elkarrekin dantzatzeko asmoa duzun bezala: horiek dira gure asmo konpartituak barne hartzen dituzten asmo indibidualak. Garrantzizkoa da asmo hauek ohikoak, asmo indibidualak bezalakoak, direla azpimarratzea: horietan berezia dena edukia da alegia. Ez da beharrezkoa beraz asmo mota espezifiko batez (Searleren (1990) araberako «Gu-asmoak» edo) baliatzea.

Baina demagun guk ez dugula soilik elkarrekin dantzatzeko asmoa eta, testuinguru orokorrago batean, elkar maitatzen dugula. Maitatze hori harreman sozial aktiboa den heinean (praktika sozial anitzetan adierazten dena, adibidez, zenbait egoera kulturaletan, elkarrekin dantzaren bitartez): esan al genezake orduan emozioei paper espliziturik ematen ez dion ekintzaren teoria batek elkar maitatze hori «jendetasun modestu» delakoaren parte bezala trata dezakeela? Egileak soberan daki (liburuan zehar errepikatzen baitu) bere teoria «kasu zentraletara» egokitzen dela. Baina, hala ere, elkar maitatzea Bratmanek erabilitako kasua da jada lehendabiziko kapituluaren hasieratik. Zentzu honetan kuriosoena, 41. orrialdean agertzen diren borondate ahuleko maitaleen bikotea da: affair bat edukitzeko asmoa parteka dezakete, dio Bratmanek, nahiz eta bakoitzak hori aukera hoberena ez dela pentsatu ${ }^{4}$.

ahala espontaneo eta malgu izateko») dituela onartzen du, planifikazio estrukturetan jarritako enfasia giza agenteen karikatura batera (etengabe planak egiten dituzten izaki zurrunak) eramateko arriskua errekonozituz. Alta, denboran zeharkako antolakuntza forma sakonen eraketa eta jarraipena giza agenteen inguruko gertaera nabarmena denez, eta bertan planak egiteko gaitasunak zentralak direnez, ekintzaren teorian emandako enfasia justifikatua geratuko litzateke nolabait.

${ }^{4}$ Nabaria denez, egileak bestelako auzi bat tratatzeko erabiltzen du adibide hori, eta inolaz ere ez ekite sozialen formazioan eta azalpenean emozioek duten garrantziaren harira. 
Batek asmoek pertsonaren psikologiaren «osagai» emozionalak subsumitu egiten dituztela, edo asmoak emozioz ere osatuta daudela, pentsatu behar $\mathrm{du}$, adibideari zentzu errealistago, ez hain 'robotiko', bat emateari begira. Asmo, plangintza eta jarduera kolektiboetan emozioek duten rola esplizitatzea faltan botatzen da (kontu hauetaz ari diren ia guztien antzera) zentzu honetan.

Bestalde, jarraikortasun tesia delakoan, irakurlea azalpenaren abstrakzio mailaren ondoriozko ilusioetan eror daitekeela deritzot. Alegia, maila soziala indibidualetik «agertzen» («to emerge») dela (sarritan) irakurtzerakoan, plano indibidualean «soziala» den hori inexistentea dela uste izatearen ilusioa. Bratmanek badaki, noski (are gehiago liburu honen parte bihurtutako aurreko artikulu bati egindako komentario kritiko batean, Pierre Demeulenaerek (2008) kontua nabarmendu zuenean), arrazionaltasun eta arauen kasuan, «banakakoa»ren eta «soziala»ren arteko ebaketarik ez dagoela.

Oinarrian, bere eraikuntza kontserbadorea gauzatzeko, hots, ekite jakin baten $(J)$ asmo partekatuarentzako baldintza nahikoak emateko, Bratmanek oinarrizko tesi bakar horren bi bertsio eskaintzen ditu. Bigarren bertsio «konprimitua» jarraituz (102. or.), oinarrizko tesiak honako ideia-sarea osatuko luke: (A) asmo-baldintza: gutako bakoitzak guk $J$ egiteko asmoak ditu; gutako bakoitzak guk $J$ egiteko asmoak ditu gure guk $J$ egiteko asmoak direla eta (kateatze eta erreflexibitatea) eta ekintzaren zein honen azpi-planen elkarrekiko erantzukizun nabaria dela eta; (B) uste-baldintza: gutako bakoitzak uste du bakoitzaren $J$ sustatzeko asmoak jarraituz gero, guk $J$ egingo dugula asmo horiei esker zein azpi-lanetan eta ekintzan elkarrekiko erantzukizun nabariari esker, eta bakoitzak gure $J$ egitearen aldeko bakoitzaren asmoen iraunkortasunean elkar-mendekotasuna dagoela uste du; (C) elkar-mendekotasunaren baldintza: gure $J$ egitearen aldeko bakoitzaren asmoen iraunkortasunean elkar-mendekotasuna dago; (D) ezagutza komunaren baldintza: (A)-(D) ezagutza komuna dira. Honez gain, ekite partekatu intentzionala (finean, «modest sociality») emango da (E) baldintza emanez gero, hots: (E) elkarrekiko erantzukizunaren baldintza: gure $J$ egiteko asmo partekatuak gure $J$ egiteko azpi-asmo eta ekintzen elkarrekiko erantzukizunaren bitartez bideratzen du gure ekitea, azken horrek konpartitutako ekitearen aldeko bakoitzaren asmoen bitartez bakoitzaren ekite konpartitua bakoitzak bilatutako helburua markatzen duelarik. Horrela, azkeneko baldintza honek lehenengo bietan elkarrekiko erantzukizuntzat zer jo behar den espezifikatzen du.

Ekintza konpartituak banako ezberdinen plangintza-estruktura indibidualen funtzionamendu arrazionala zein eduki jakinen asmo eta usteen arteko erlazioa eskatzen du. Usteak presente dauden arren, fenomenoaren funtzionamenduaren bereizgarria asmoak (zehazki, bere edukiak eta hauen pertsonen arteko elkar loturak: aipatutako kateatze, saretze, etab.) dira. 
Bestalde, asmoen banakoen arteko elkar loturak inplikatzen duen elkar ezagutzak ez du zertan (esentzialki) elkarrekiko obligaziorik (obligazio moralik, ulertzen da) ekartzen. Horiek maiz ager daitezke, baina puntu honetan zentrala den ezaugarria elkar dependentziaren iraunkortasuna da. Eredu honetarako funtsezkoa den araudia arrazoiaren berezko arauetan islatzen da, bai maila indibidualean bai sozialean. Azkenengoen kasuan, arrazionaltasun indibidualaren arauen eta berezko asmoen edukien arteko interakzioan oinarritzen dira. Jendearen ekite partekatuak ez dira, baina, akordioen ondoriozko obligazioengatik azaltzen: esandakoaren bidean ekiteko asmoa izan behar baititu jendeak eta (obligazioak betetzeko asmo falta ohikoa dela badakigu). Asmo konpartituak, eta ez elkarrekin hartutako obligazioak, dira eskala txikiko sozializazioaren barnean emandako ekintza azaltzeko giltza.

Gu elkarrekin dantzatzen ari garenean, elkarri (lotura sozio-psikologikoekin) lotutako agente plangile gisa ikusten gaitu Bratmanek. «Gu», hots, subjektu gramatikala. «Gu»: partaideen barnetik antolatutako estruktura (dantzaldiaren iturri kausala dena). Subjektibitateari dagokionez, «holismo moderatu» bat mantentzen du egileak: gure dantzaldian osatzen dugun bikoteak («gu») ez du «subjektu kolektibo» bat osatzen. Zentzu honetan, agentzia eta subjektibitatea bereizten dira: modu egokian estrukturatutako banakoen sorta batek talde agente bat osa dezake (bere ekitearen ondorioen erantzule), banako bakoitzaren estruktura psikologikoan emandako asmo eta bestelako jarrera konpartituen subjektu den entitatea osatu gabe.

Azkenik, talde-deliberazioaz ere hitz egiten du Bratmanen teoriak. Konpromiso partekatuak agertzen dira elkarrekin ematen diren hausnarketa prozesuetan. Kontsiderazio batzuek beste batzuek baino pisu handiagoa edukiko dute. Konpromisoek testuinguru jakinetan kontsiderazio jakinei pisua emango diete, "pisutsutzat» tratatuko dituzte, talde-politika konpartituak hartuz. Puntu honetan interesgarriena Bratmanen hurbilketa teorikoak duen «pluralismoa» da: talde bateko partaideek kontsiderazio jakinen pisuaren inguruko politika partekatua izan dezakete, bai, horrek euren juzgu edo ebaluazio pertsonalen partekatzea suposatu gabe. Era berean, taldekide ezberdinek ekite partekatuak burutu ditzakete, parte hartzeko asmoen arrazoiak edota motibazioak kasu bakoitzean ezberdinak izanik. Bratmanek bere teoriaren bertutetzat jotzen du (140. or.) —eta, nire ustez ere, bada - bateratze sozial partzial baina substantibo hori modelatzeko gaitasuna. Aurretik (91. or.) partzialtasun sozialaren nonahikotasunaz hitz egiten du. Haatik, bereziki kultura liberalaren ezaugarria dela ere esaten du, «gure» bizitza sozialaren ezaugarrien parte. Honek bere teoriak «gizarte pluralisten» berezko espezifikotasuna ez duten eredu sozialei begira eduki lezakeen baliagarritasunaren maila zein izango litzakeen galdetzera eramaten gaitu. Edonon, beti eskala txikietan bada ere, aplika daiteke honako eredu hau? 
Elkarrekin ekitearen plangintza-teoriak bere aplikazio-eskala oso ondo mugatzeari zor dio bere dotorezia nabarmena. Ekite sozial «apal» batetik harago, egungo bizitza sozial «masiboan» gertatzen diren hartu-emanen estruktura islatu nahi izatekotan, teoria honek ezintasun teorikoekin topo egingo luke dudarik gabe. Antzeko zerbait gertatuko litzateke, teoria bere horretan mantenduz gero behintzat, autoritate erlazio edo asimetria gogorretan oinarritutako ekite kolektiboak kontsideratzerako orduan ${ }^{5}$. Scott Shapirok (2014), adibidez, bi bariazio horiek hartzen ditu kontuan. «Masiboki partekatutako jarduera» (elkarrekin ekiten duten asmo konpartiturik zein konpromisorik gabeko partaide «alienatuz» osatutakoa, egungo korporazio erraldoietan ohikoa dena, hain zuzen) izendatzen duen kasu mota, dio Saphirok, Bratmanen teoriatik harago geratzen da. Honek ez du, noski, Bratmanen atentzioa zentratzen duen eskala «apalaren» tratamendua desegoki bihurtzen. Hala ere, jarduera masiboak egungo «masa» gizarte garatuen ekite modu espezifikoak (nahiz eta ez bakarrak) izanik, ekintzaren filosofiak planteatutako ereduak oraindik ere soilik eskala txikian (eta adibide mota ia anekdotikoez baliatuz) mantendu eta erreproduzitzea deitoragarria dela deritzot —apalki.

Bere mugen baitan, edozein kasutan, aurkeztutako teoria zuhurra da, neurrizkoa. Ekonomikoa, gehitu behar ez dituen elementu teoriko berrietara erreparatzen badugu. Elegantea, bermatu nahi duen plano indibidual eta sozialaren arteko jarraikortasun (kontzeptual, metafisiko, normatiboa) dela eta. Jarduera filosofikoan, David Lewisen (1973) arabera, «kualitatiboki neurrizkoa» (hots, entitate mota funtsean ezberdinen kopuru minimoa bilatzea) izatea ona bada, ezaugarri on batekin eratutako teoriarekin egingo du topo irakurle interesatuak.

\section{Erreferentzia bibliografikoak}

Demeulenaere, Pierre (2008). «Where is the Social?», in Philosophy of the Social Sciences: Philosophical Theory and Scientific Practice, Chris Mantzavinos (Arg.), Cambridge: Cambridge University Press, 60-66 or.

Lewis, David D. (1973). Counterfactuals, Oxford: Basil Blackwell.

\footnotetext{
5 Bestalde, hertsadura kasuak jasotako tratamendurako, ikus. lehenengo kapituluaren 10. atala (37-39). Hemen autoreak jarduera intentzional konpartituen izaera intentzionala jarduera konpartituen izaera kooperatibotik bereizteko premia erakusten du. Gauzak horrela, hertsadurapeko jarduera kolektiboak intentzionalak lirateke kooperatiboak izan gabe eta, bestelako jarduera intentzional konpartituak bezala, gure elkarrekin pentsatu eta ekitean antolaketa sozial-psikologiko mota bereizgarri baten ideia dakar, besterik gabe. Arazoa, dirudienez, kooperazioak (edo bere faltak), nozio gisa, dakarren moralizazio maila litzake. Edozein kasutan, Bratmanen teoriak erlazio asimetrikoz osatutako ekite kolektiboei eskainitako tratamendua faltan botatzen da.
} 
Saphiro, Scott J. (2014). «Massively Shared Agency», Rational and Social Agency: Essays on The Philosophy of Michael Bratman, in Manuel Vargas eta Gideon Yaffe (Arg.), New York: Oxford University Press, 257-293 or.

Searle, John (1990). «Collective Intentions and Actions», in Philip R. Cohen, Jerry Morgan \& Martha Pollack (Arg.), Intentions in Communication, Cambridge: MIT Press, 401-415 or.

Vargas, Manuel eta Gideon Yaffe (2014). «Introduction», Rational and Social Agency: Essays on The Philosophy of Michael Bratman, in Manuel Vargas eta Gideon Yaffe (Arg.), New York: Oxford University Press, 1-11 or.

Zvonko Díaz

ILCLI 
